\title{
GEOMORFOLOGÍA DEL ÁREA DE PUTRE, ANDES DEL NORTE DE CHILE: ACCIÓN VOLCÁNICA Y CLIMÁTICA EN SU MODELADO*
}

\author{
GEOMORPHOLOGY OF THE PUTRE AREA, NORTHERN ANDES \\ OF CHILE: VOLCANIC AND CLIMATE ACTION IN ITS MODELING
}

\author{
Alan Rodríguez Valdivia**, Cristián Albornoz Espinoza ${ }^{* * *}$ y Alejandro Tapia Tosetti ${ }^{* * * *}$
}

\begin{abstract}
El área de Putre se localiza en una subcuenca de montaña a $3.500 \mathrm{msnm}$, en la vertiente oeste de la cordillera occidental Andina (extremo norte de Chile), en el que predominan formas de relieve asociadas a la acción volcánica y del clima. Dicho relieve es producto de la evolución geológica del Complejo Volcánico Taapaca (CVT), cuyos procesos eruptivos han dado paso a morfolitologías constructivas que configuran la subcuenca estudiada, en las que el factor climático ha actuado constantemente, meteorizando y erosionando los materiales, dando como resultado formas derivadas de procesos gravitacionales, fluviales y, en menor medida, periglaciales. Se reconoce en el modelado existente, la acción ejercida por procesos de tipo gravitacional que se han traducido en movimientos en masa de tipo derrumbes y flujos de detritos, mientras que la acción fluvial ha favorecido la formación de profundas y angostas quebradas en el área.
\end{abstract}

Palabras claves: Putre, Complejo Volcánico Taapaca, Geomorfología, Movimientos en masa.

The Putre area is located in a sub-basin at an altitude of 3,500 $\mathrm{m}$ on the west slope of the Western Andean mountain range (in the northernmost part of Chile), with volcanoes and the climate forming the predominant landforms. This relief is the result of the geological evolution of the Taapaca Volcanic Complex (CVT) whose eruptions have given rise to constructive morpho-lithologies shaping the sub-basin, and the climate consistently weathering and eroding, leading to forms which resulte primary from gravitational and fluvial processes and secundary from periglacial mechanisms. The existing model recognized both the action exerted by gravitational processes that have resulted in slumps and debris flows, and by fluvial action that has favored the formation of deep and narrow gorges in the area.

Key words: Putre, Taapaca Volcanic Complex, Geomorphology, Landslide.

\section{Introducción}

Las formas de relieve precordilleranas y altiplánicas de la región de Arica y Parinacota se caracterizan por un dominio de estructuras originales volcánicas. En el área precordillerana (sierra) se reconocen una gran variedad de accidentes geográficos que, producto de la subducción de la placa de Nazca bajo la Sudamericana, han originado relieves fallados y volcánicos. Mientras que el área altiplánica se caracteriza por presentar un relieve predominantemente llano, sobre los $3.800 \mathrm{msnm}$, plateau riolítico terciario asociado a volcanismo fisural en el que sobresalen imponentes macizos volcánicos, relacionados a un volcanismo de tipo central cuaternario y que a su vez forman parte de la cordillera occidental en los Andes del Norte de Chile. Entre los principales y más estudiados macizos se distinguen los volcanes
Pomerape, Parinacota (Clavero et al. 2002, 2004b; Wörner et al. 1988), Tacora, Guallatiri (Watts et al. 2014) y Taapaca (Clavero et al. 2004a; Clavero y Sparks, 2005; Clavero 2007).

En este contexto, el Complejo Volcánico Taapaca (CVT), posee la particularidad de situarse en el margen entre la precordillera y el altiplano. Hacia el flanco suroccidental del complejo volcánico se presenta el valle-quebrada de Putre, con un paisaje serrano modelado por estructuras tectónicas y volcánicas, área propicia para la generación de procesos de movimientos en masa, los que suelen modificar los rasgos geomorfológicos preexistentes (Rodríguez et al. 2014). Según Golubev (1969) y Hauser (1993), los espacios de montaña en Chile tienen las condiciones para que se generen movimientos en masas, y cuyo ejemplo más representativo en los sectores próximos al área estudiada son los

\footnotetext{
* Universidad de Tarapacá. PROYECTO Nº 1615-5731-11 y Proyecto FONDECYT No 1150701.

** Investigador independiente, Arica, Chile. Correo electrónico: geoculturaluta@ gmail.com

*** Heidelberg Center para América Latina. Santiago, Chile. Correo electrónico: albornoz@ uni-heidelberg.de

***** Universidad de Tarapacá, Departamento de Ciencias Históricas y Geográficas. Arica, Chile. Correo electrónico: atapia@ uta.cl
} 
deslizamientos rotacionales de grandes magnitudes reconocidos en el valle-quebrada de Socoroma (Montecinos, 1962) y constantes flujos de detritos que afectan a la localidad de Putre en temporada estival (Figura 8).

Las investigaciones llevadas a cabo por Clavero et al. (2004a) y Clavero y Sparks (2005) demuestran que el Complejo Volcánico Taapaca, está lejos de ser un centro eruptivo extinto, pues este complejo volcánico ha tenido actividad eruptiva persistente y cíclica. A su vez explican que el volcán evidencia una evolución, la que dividen en cuatro estadios: El estadio I (¿Plioceno superior?-Pleistoceno inferior), que se inicia con un domo compuesto por lavas de andesitas, pasando luego a un domolava inclinado; el estadio II (Pleistoceno inferior a medio; 1,5-0,5 Ma) presentó un domo complejo asociado a escombros y depósitos piroclásticos; en las etapas III (Pleistoceno medio; 0,5-0,47 Ma) y IV (Pleistoceno medio-Holoceno; $<0,45 \mathrm{Ma}$ ), la evolución del complejo volcánico manifestó moderados cambios de composición magmática y una evidente migración de la actividad eruptiva en sentido sur suroeste (SSW).

Trabajos previos corresponden a estudios geológicos-vulcanológicos realizados por Clavero y Sparks (2005) y García et al. (2004), en los que se reconocen depósitos volcanoclásticos y sedimentarios aluviales-coluviales. Los depósitos volcanoclásticos son producto de las violentas erupciones del CVT $\mathrm{y}$ de antiguas erupciones que dieron paso a las secuencias volcanoclásticas de la formación Lupica. Mientras que los depósitos aluviales-coluviales, corresponden a material meteorizado y erosionado de los relieves estructurales originales, que fueron desplazados hacia niveles topográficos inferiores.

El presente trabajo aborda la configuración geomorfológica del piedemonte suroccidental del Complejo Volcánico Taapaca, la que ha estado condicionada hasta la actualidad por factores geomorfológicos de tipo volcánico y climático. Para tal fin se abordó un estudio geomorfológico descriptivo-paisajístico del área estudiada, que en este trabajo se ha denominado "Subcuenca hidrográfica Putre" (Figura 1).

\section{Área de estudio}

El estudio comprende la denominada área de Putre, ubicada en la región de Arica y Parinacota (extremo norte de Chile), considera específicamente el pequeño valle-quebrada situado en la precordillera o sierra de Arica (18 ${ }^{\circ} 11^{\prime} \mathrm{S} / 69^{\circ} 33^{\prime} \mathrm{W}, 3.500 \mathrm{msnm}$ ), que se encuentra inmediatamente al oeste de la meseta altiplánica y al este de la Depresión Intermedia (Börgel 1983). La precordillera en este sector se caracteriza por sus estribaciones desprendidas del cordón occidental de la cordillera de los Andes, conformadas a partir de acción tectónica y volcánica, así como también por procesos morfológicos derivados de numerosos aluviones desencadenados en el área (Seyfried et al. 1998).

Las condiciones climáticas corresponden a las propias de un desierto marginal de altura con tendencia tropical (Fuenzalida 1965), que destaca por la ocurrencia de precipitaciones convectivas en el período estival y asociadas al fenómeno monzónico que se presenta en el verano del hemisferio sur en el interior sudamericano (Aceituno, 1993; Mendonça, 2013). El área presenta una precipitación anual aproximada de $195 \mathrm{~mm}$, que se concentra de diciembre a marzo, la temperatura influida por la altitud presenta valores medios mensuales que fluctúan, entre 6 y $9^{\circ} \mathrm{C}$; sin embargo si se consideran los valores absolutos, las amplitudes son muy marcadas, oscilando entre valores inferiores a 0 ${ }^{\circ} \mathrm{C}$ y superiores $20{ }^{\circ} \mathrm{C}$. Estudios recientes acerca de investigación del cambio climático en el área del extremo norte del país, junto con evidenciar condiciones de alta irregularidad intraestacional e interanual de la precipitación, muestran una tendencia a su reducción, principalmente en la zona altiplánica (Bennett et al. 2016; Sarricolea et al. 2015); para las temperaturas se ha detectado modificaciones que muestran un ascenso en los valores medios para las últimas décadas, situación que no está presente en sectores cordilleranos, registrándose solo un significativo incremento en las temperaturas mínimas (Meseguer-Ruiz et al. 2016).

Hidrográficamente esta área corresponde a la quebrada de Putre, que nace a partir de una serie de aguadas originadas en los bofedales (vegas) al pie del Complejo Volcánico Taapaca, curso de agua que forma parte de la cuenca del río Lluta, el sistema hidrográfico más importante de la XV Región, que drena una superficie que alcanza a $3.378 \mathrm{~km}^{2}$, con una longitud aproximada de $160 \mathrm{~km}$ (Niemeyer y Cereceda 1983; JICA 1995).

El Complejo Volcánico Taapaca (en lengua aymara tata T'apaka o Tapakaxa, "ave invernal de rapiña" o "nido de ave invernal"), denominado 


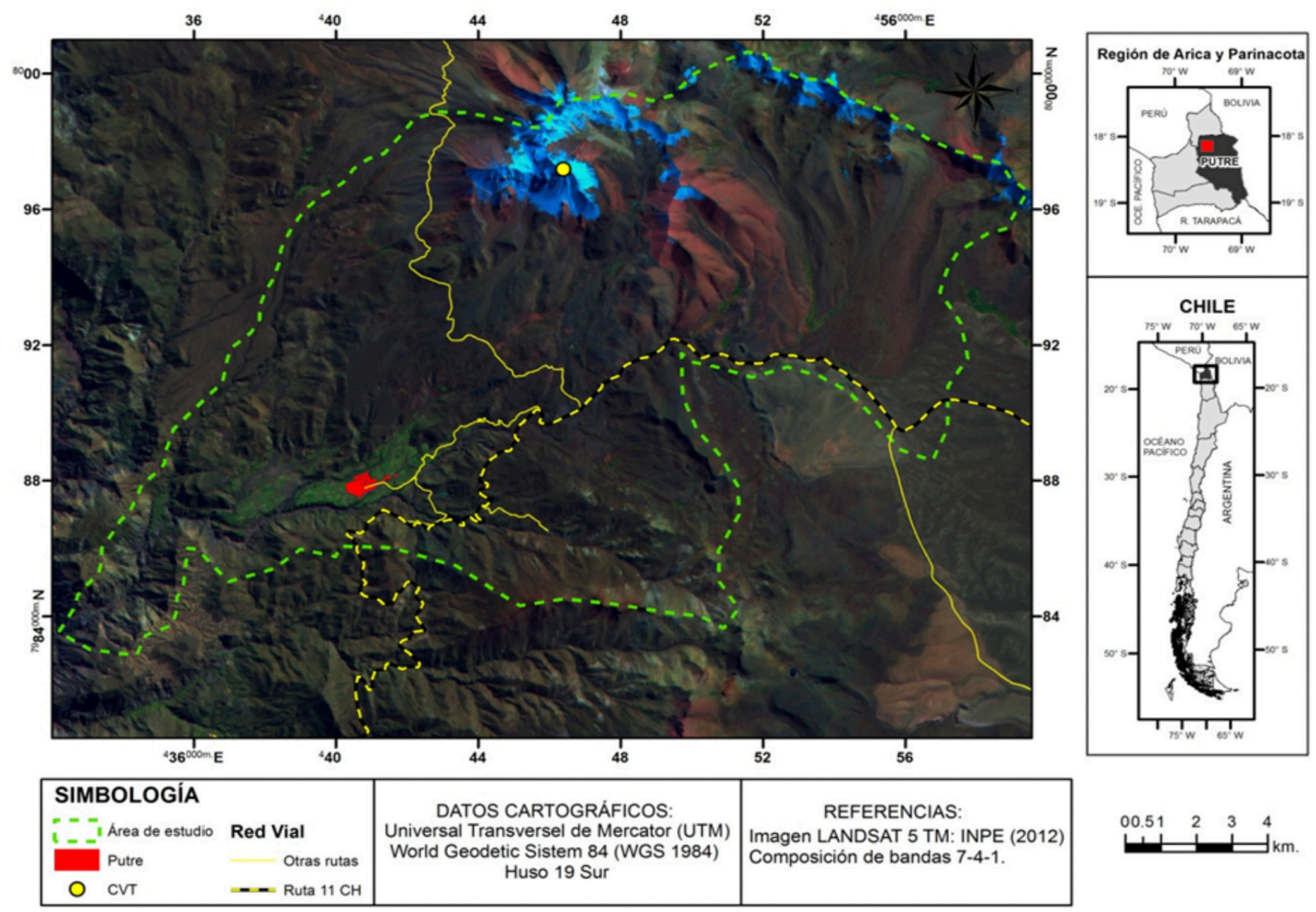

Figura 1. Área de estudio correspondiente a la subcuenca de Putre. Fuente: elaboración propia.

también Nevados de Putre, se ubica en el margen occidental de los Andes del extremo norte de Chile. Este macizo volcánico se emplaza en los $18^{\circ} 06^{\prime} \mathrm{S} / 69^{\circ} 30^{\prime} \mathrm{W}$, con una cumbre cercana a los $5.850 \mathrm{~m}$ s.n.m. (correspondiente al cerro Taapaca), constituye la orografía de mayor altitud de la precordillera del río Lauca (Börgel 1983). Este complejo volcánico cubre una extensión aproximada de $250 \mathrm{~km}^{2}$ y su edificio principal ocupa un volumen aproximado de $35 \mathrm{~km}^{3}$ (Clavero y Sparks 2005).

\section{Metodología}

La presente investigación fue abordada desde un enfoque centrado en el análisis geomorfológico de los aspectos paisajísticos existentes en el área de estudio, con la idea de destacar la génesis y los procesos que han actuado en la configuración del relieve actual, para ello se realizaron varios pasos, sintetizados a continuación.

Se recolectó información bibliográfica relacionada al área de Putre, al Complejo Volcánico Taapaca (CVT) y de movimientos en masa en la precordillera de Parinacota, sumándose a ello el análisis de imágenes de satélites Landsat 5 TM y un modelo digital de terreno AsterGDEM, que permitió obtener un mapa geomorfológico preliminar del área. Posteriormente, mediante trabajo de campo se contrastó la información de gabinete con los datos de terreno, como distancias, superficies, diferencias de altitud, gradiente de las laderas y dirección de los depósitos. Finalmente, junto con el análisis e interpretación de la información obtenida, se confeccionó una carta geomorfológica del área, escala 1:60.000, siguiendo las recomendaciones de Otto y Smith (2013); Otto et al. (2011); Seijmonsbergen y Graff (2006); y Otto y Dikau (2004) para cartografía geomorfológica en áreas de montaña.

\section{Geomorfología del área estudiada}

\section{Morfoevolución y morfodinámica endógena}

Las formas volcánicas que se observan son producto de diferentes etapas evolutivas que ha experimentado el CVT, que constituyen las formas 
estructurales primitivas del relieve, resultantes del fenómeno de subducción producido por la dinámica tectónica asociada a la interacción entre las placas litosféricas de Nazca y Sudamericana.

La extrusión de material volcánico incandescente, que ha migrado hacia el suroeste en los últimos $450 \mathrm{ka}$, ha formado varios domos, entre los que destaca el domo de la unidad Socapave (25-9 ka) y el domo de la unidad Putre ( $>9$ ka AP), ambas unidades correspondientes a la etapa evolutiva IV del CVT (Clavero y Sparks, 2005) (ver Figuras 2, 3 y 4). Esta última etapa es la más relevante para este trabajo, porque corresponde al período en que se produjeron, con sentido suroeste, las avalanchas volcánicas de mayor extensión longitudinal, avance ocurrido hacia los sectores donde actualmente se emplaza la localidad de Putre y otros asentamientos humanos menores, así como las áreas de cultivos y parte de la ruta internacional $11-\mathrm{CH}$.

Los colapsos volcánicos que se produjeron durante el Estadio IV (> $450 \mathrm{ka}$ ), en el que se reconocen las unidades Churilinco (450-430 ka), Tajane (430-25 ka), Socapave (25-9 ka) y Putre (>9 ka), crearon una morfología hummocky landscape (cerrillos formados por colapsos volcánicos) en las proximidades al edificio volcánico. A su vez, en los sectores más distales la topografía se vuelve menos caótica e irregular, creando finalmente una morfología de terrazas, producto del efecto erosivo lineal de flujos detríticos densos en los depósitos de las avalanchas volcánicas (Siebert 1984) (Figuras 2 y 7). La erosión y el depósito de nuevos materiales volcánicos desgastaron y sepultaron algunas de las formas típicas de avalancha volcánica, sin embargo, todavía es posible distinguir ese tipo de morfología en los sectores sur-suroeste del CVT. Este tipo de morfología es reconocible en otros depósitos volcánicos de la Zona Volcánica Norte de Chile, como ocurre en el caso de los volcanes Parinacota (Clavero et al., 2002; Clavero et al., 2004b), Tata Sabaya (Godoy, 2008) y Llullaillaco (Rodríguez, 2010).

Se pueden distinguir tres sectores de depósitos de flujos piroclásticos descritos por Clavero y Sparks (2005), los que se presentan en los flancos norte, sur y suroeste del complejo volcánico. El primero, corresponde al Estadio II de la historia evolutiva del CVT, con formas de conos en el flanco norte, los que, producto de las aguas no encauzadas, han sido desgastados formando un extenso glacis hasta los sectores próximos al río Lluta. El segundo pertenece

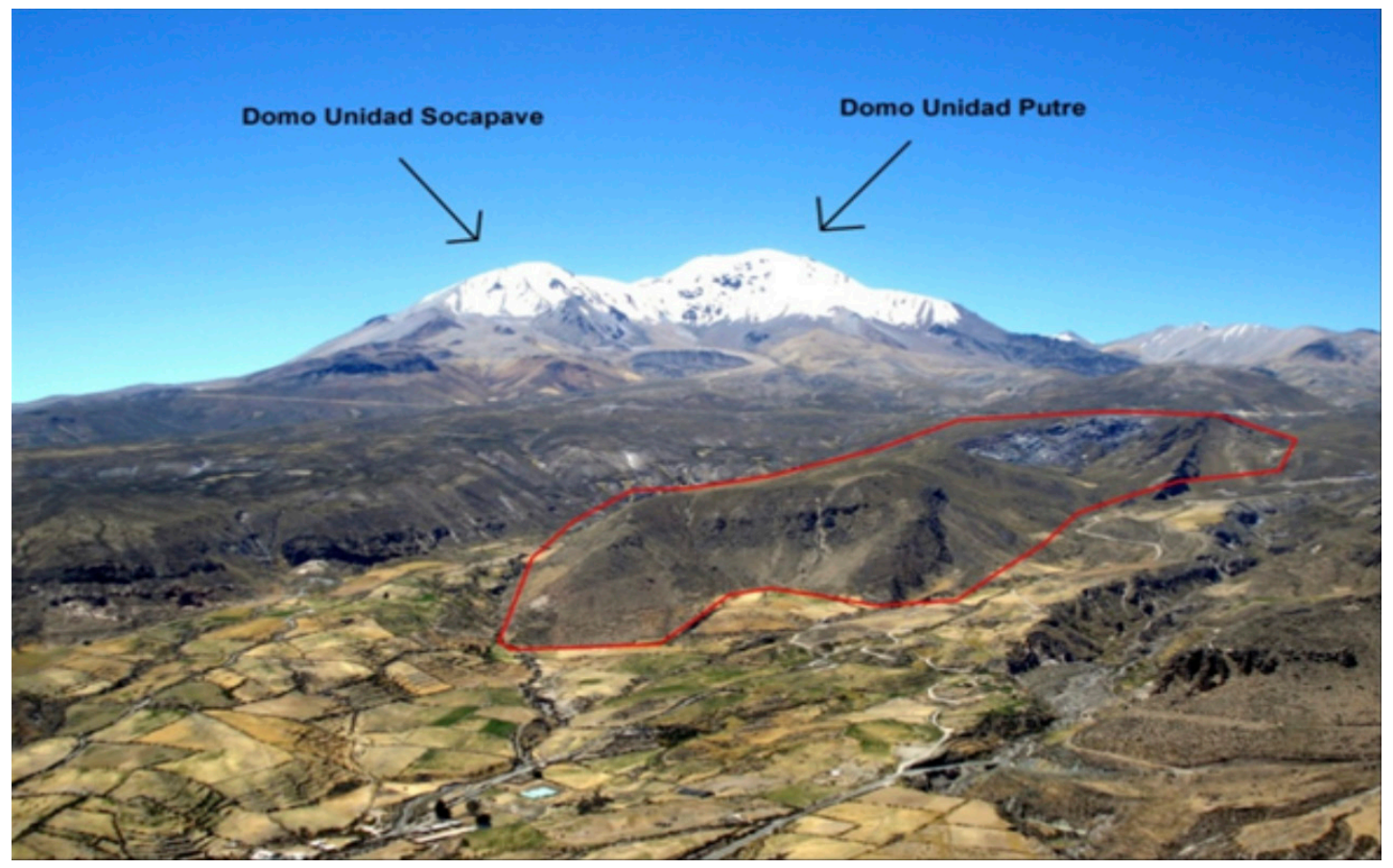

Figura 2. Al fondo los domos que conforman los Nevados de Putre, en la parte inferior se distinguen sectores de cultivo de Putre, los que se ubican sobre depósitos volcánicos y flujos piroclásticos del CVT, que presentan una morfología típica de terrazas terminales de avalancha volcánica. El polígono de líneas rojas delimita roca del basamento que no fue sepultada por las erupciones. Fuente: Registro personal. 


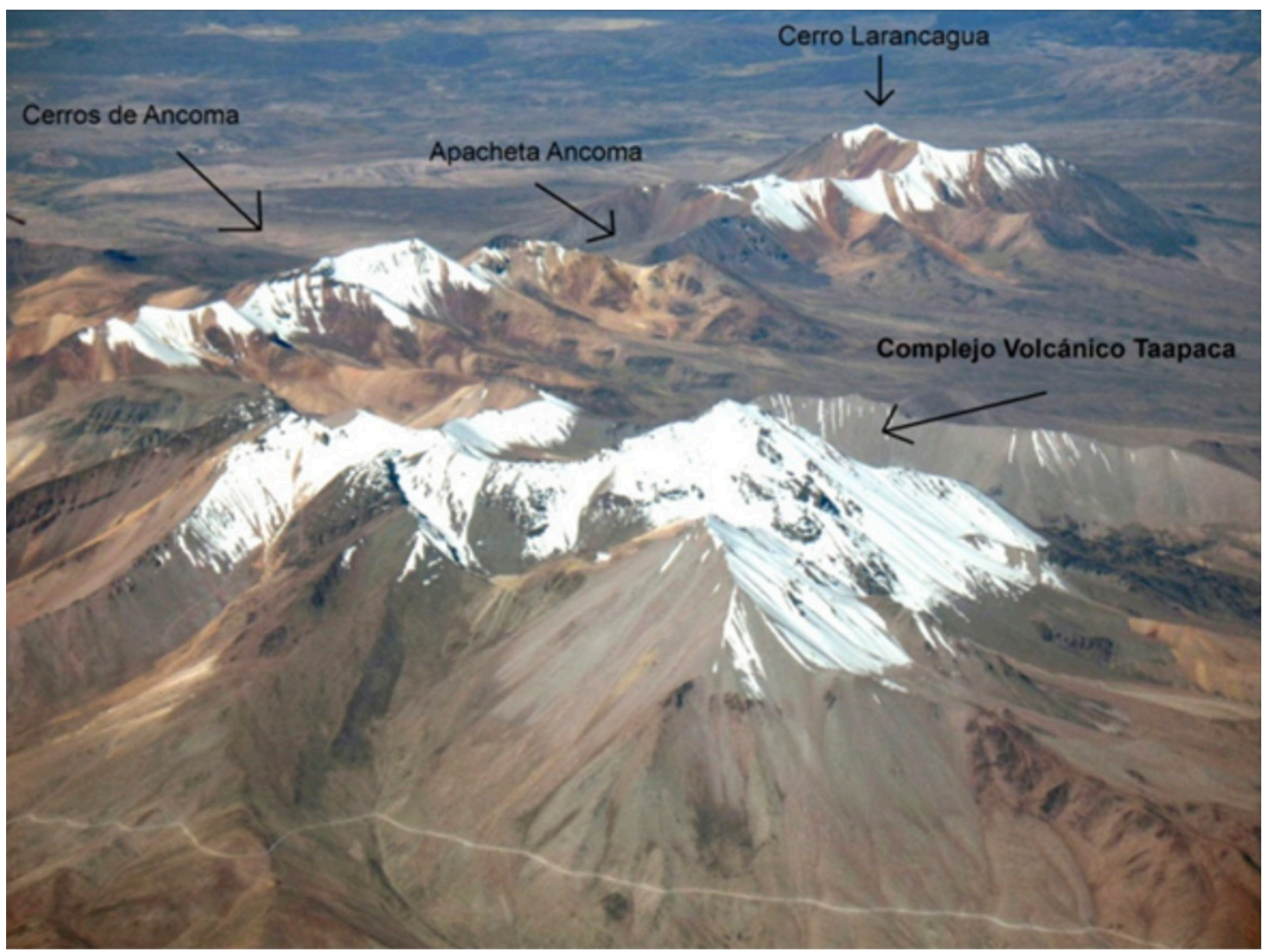

Figura 3. Cordón montañoso que se extiende de oeste a este, en primer plano se observan los domos volcánicos del CVT y, más atrás, los cerros de Ancoma, la Apacheta Ancoma y el cerro Larancagua, respectivamente. Fuente: Juan Francisco Bustos. https:// www.panoramio.com/user/1506861?photo_page=266

a los depósitos de las unidades Tajane y Putre que se encuentran muy bien preservados. El tercero se ubica en el flanco sur-occidental, corresponde a las unidades Tajane, Socapave y Putre, han rellenado antiguos paleocanales y topografías irregulares de avalanchas volcánicas, además han formado relieves de pendientes suaves cuyos testigos son terrazas terminales de flujos de escombros, representativas de grandes depósitos de avalanchas y flujos piroclásticos (Figura 7). Precisamente, la localidad de Putre se emplaza en la terraza formada por la avalancha volcánica terminal de la Unidad Tajane, correspondiente al Estadio IV del CVT.

\section{Morfogénesis de movimientos en masa}

Sobre formas de origen volcánicas actúan ciertos procesos gravitacionales que transforman el modelado de las laderas existentes en el área de estudio, dando como resultado depósitos sedimentarios coluviales, producto de la erosión de los materiales del basamento altiplánico y de los volcanes recientes del Pleistoceno Superior-Holoceno.

En el periodo comprendido entre diciembre a marzo, la meseta altiplánica y los sectores precordilleranos de la región se encuentran expuestos a condiciones climáticas diferentes a las predominantes de abril a noviembre que se caracterizan por ser meses más secos. En temporada estival la Zona de Convergencia Intertropical se desplaza hacia el Hemisferio Sur, localizándose áreas de bajas presiones próximas a la meseta altiplánica sudamericana y sectores preandinos del borde oriental de los Andes centrales. La nubosidad de desarrollo vertical asociada a masas de aire cálidas y húmedas proveniente de la cuenca amazónica se desplaza en dirección a la meseta altiplánica, donde la presencia de la cordillera de los Andes con su efecto de barrera orográfica genera las condiciones ideales para un mayor desarrollo vertical de la nubosidad. Con las altas temperaturas existentes durante el día en el altiplano, se produce la formación de 


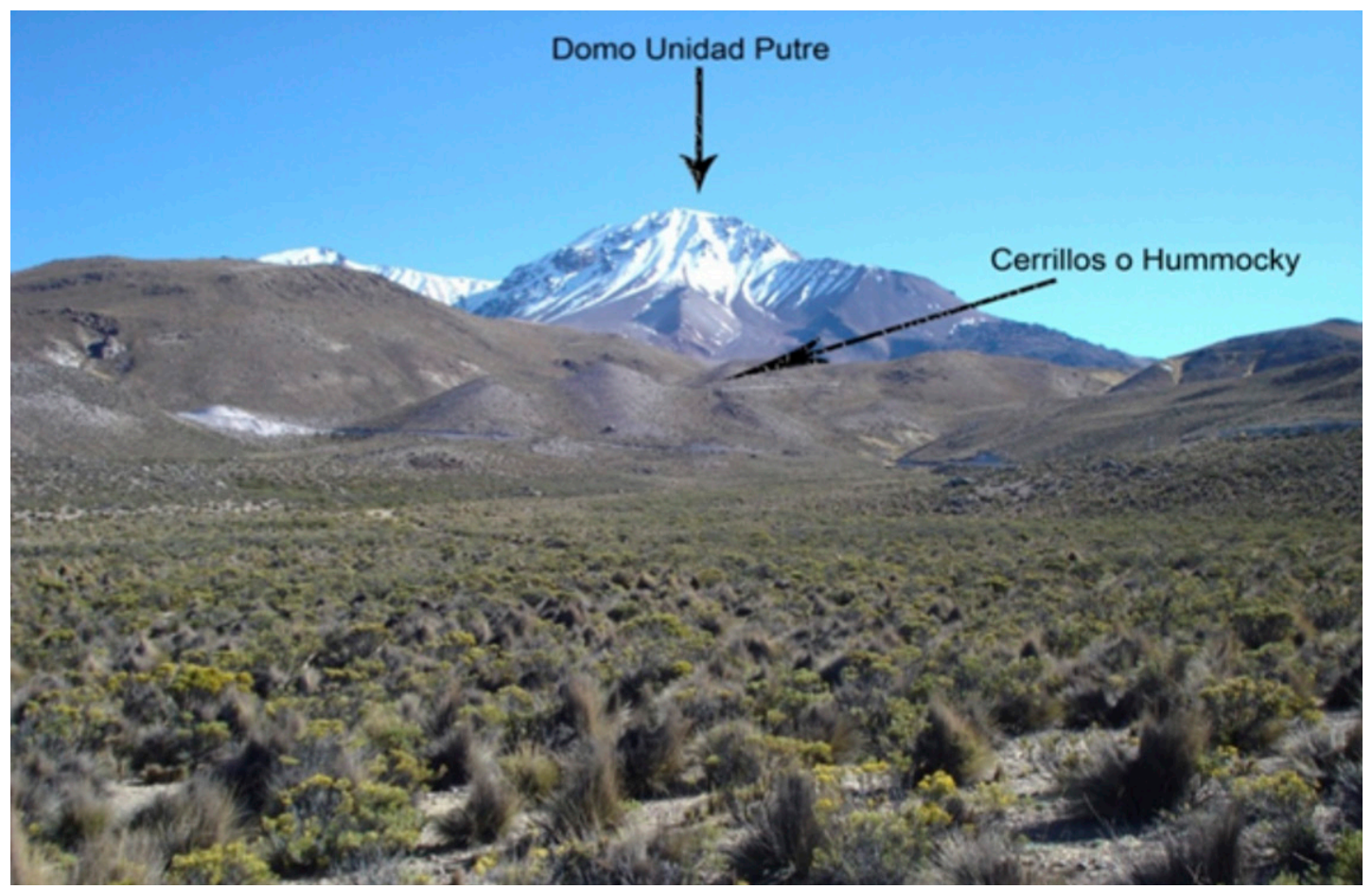

Figura 4. Vista hacia el noreste muestra el flanco Suroeste del CVT. Al fondo el domo volcánico correspondiente a la Unidad Putre (cerro Taapaca). Al centro se observan cerrillos o morfología hummocky de la Avalancha Volcánica Socapave recubiertos por flujos piroclásticos de la Unidad Putre. Fuente: Archivo de los autores.

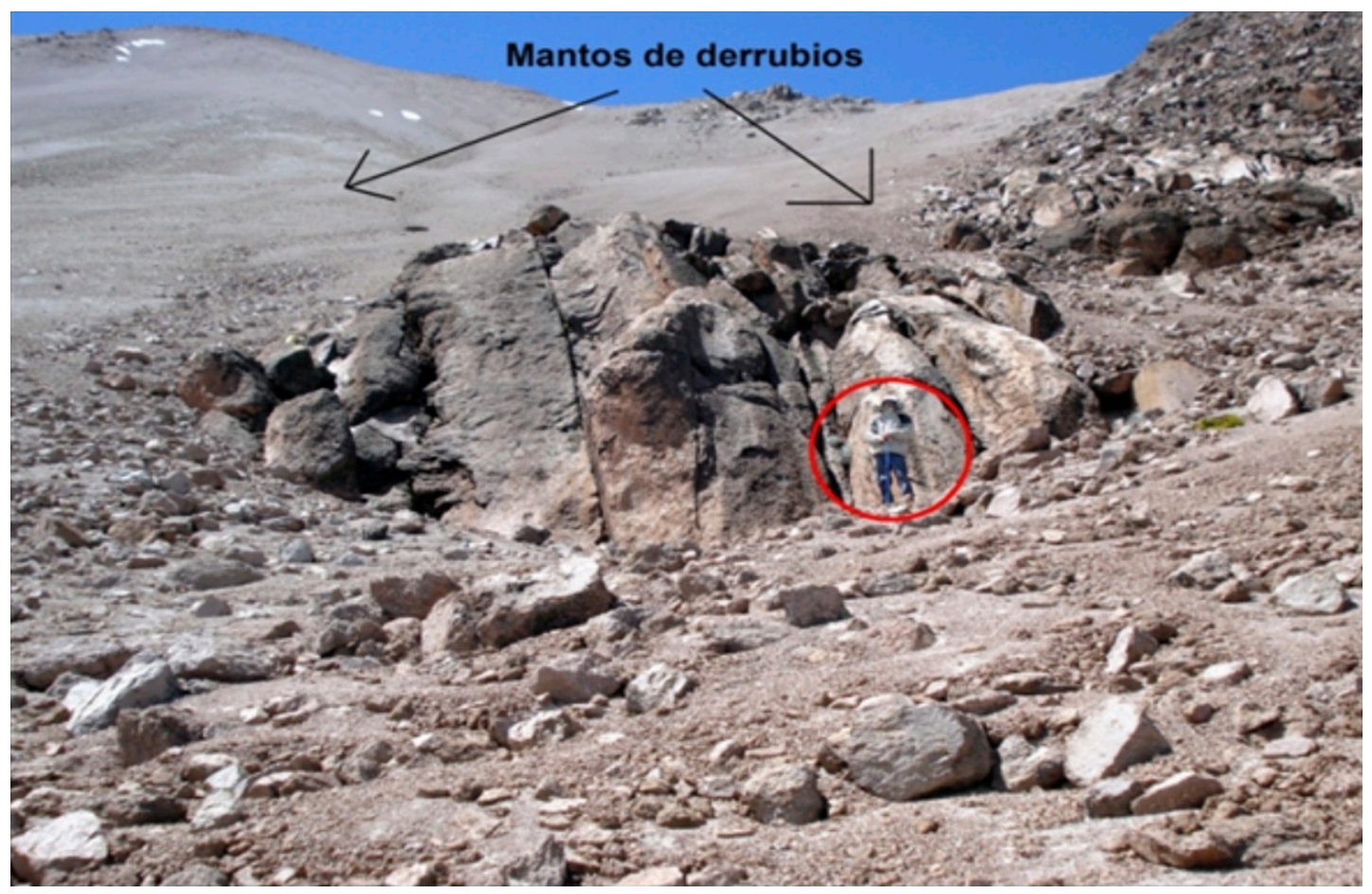

Figura 5. Vertiente suroccidental del CVT. En la imagen se distingue gran cantidad de material residual fragmentado por procesos periglaciales, lo que ha favorecido procesos gravitatorios sobre la vertiente. La persona dentro del círculo tiene una estatura de 1,79 m. Fuente: Archivo de los autores. 
cumulonimbos que generan chubascos y tormentas eléctricas que son tan características durante el período de "lluvias estivales" (Aceituno, 1993), fenómeno meteorológico que coloquialmente es mal denominado como "invierno boliviano" o "invierno altiplánico". En efecto, el registro pluviométrico de la estación meteorológica Putre demuestra que las precipitaciones en el área están concentradas entre diciembre y marzo (Tabla 1).

Durante gran parte del año en los espacios altoandinos el sistema periglacial genera material detrítico en las partes altas de las laderas, así como a consecuencia de los procesos de meteorización que afectan a la roca generalmente desnuda. Los procesos de meteorización durante los meses de abril a noviembre son principalmente producto de la crioclastía, mientras que entre diciembre y marzo este proceso se complementa con la erosión hídrica, favorecida por el aumento de las precipitaciones estivales, que se relacionan al fenómeno del monzón sudamericano (Figura 6). En ocasiones se presentan periodos estivales en los que las precipitaciones disminuyen en cantidad e intensidad y, en consecuencia, el material sedimentario generado en las laderas tiende a acumularse sobre esta, no obstante, en temporadas de lluvias intensas (diciembre a marzo) es desplazado violentamente, pendiente abajo, generándose con ello procesos de movimientos en masa con consecuencias negativas para la infraestructura vial o las actividades económicas locales.

La superficie en que predominan procesos gravitacionales corresponde al 69\% del área, convirtiéndose jerárquicamente en el proceso de mayor influencia, algo que también se puede observar en el mapa geomorfológico del área (Figura 10). A esto se agregan también los procesos geomorfológicos de ladera, los que originan surcos de erosión, flujos de detritos, derrumbes y depósitos coluviales. Estos procesos se desarrollan especialmente en los sectores aledaños al CVT y a los cerros de Ancoma, como en la cuenca baja y en el exutorio de esta.
A los procesos geomorfológicos se asocian formas como conos de detritos, caos de roca, crestas, cornisas y cordones. Los conos de detritos se relacionan principalmente a los flujos de detritos y caos de rocas, localizados estos últimos a media ladera o en partes altas de las crestas y cordones. Espacialmente, los flujos de detritos se concentran en la cuenca baja. Estas mismas formas son alimentadas por las crestas y cornisas que presentan prominentes salientes rocosos que favorecen las caídas de roca y su posterior transporte en el flujo de detrito. Este proceso en la cuenca estudiada es muy común en la zona prealtiplánica del norte de Chile (Golubev 1969; Hauser 1993; Rodríguez 2010; Rodríguez et al. 2014), donde se conjugan ciertas condicionantes geográficas, litológicas y climáticas que permiten el desarrollo y posterior evolución de las formas resultantes.

En síntesis, los procesos de movimientos en masa son fenómenos recurrentes en la topografía irregular creada por la actividad volcánica, distinguiéndose en los depósitos volcánicos, quebradas encajonadas, como también elevaciones topográficas de laderas empinadas compuestas por cornisas y taludes, que favorecen movimientos de desplazamiento y caída de rocas, cuyos testigos se ubican en la base y partes medias de la ladera (Figura 7).

\section{Morfogénesis y morfometría fluvial}

Los productos del modelado fluvial se relacionan a la acción erosiva de las corrientes perennes y episódicas del área estudiada, lo que ha originado profundas quebradas o cañones que presentan dirección de noreste a suroeste, sobresaliendo las quebradas de Taipicagua, Pacollo y Ancoma. La Figura 9 muestra cuatro perfiles topográficos, en los que se observan las importantes diferencias de altura entre el lecho del río y las laderas que componen las quebradas (mayores a $500 \mathrm{~m}$ en los perfiles de los cortes A-A', B-B' y D-D').

En los perfiles también es posible observar las formas de modelado asociadas a las quebradas.

Tabla 1. Precipitación media mensual entre 1976 y 2009, correspondientes a la estación meteorológica Putre

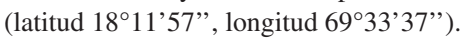

\begin{tabular}{|c|c|c|c|c|c|c|c|c|c|c|c|c|}
\hline & Ene. & Feb. & Mar. & Abr. & May. & Jun. & Jul. & Ago. & Sep. & Oct. & Nov. & Dic. \\
\hline $\begin{array}{l}\text { Precipitación media } \\
\text { mensual }(\mathrm{mm})\end{array}$ & 65,9 & 55.3 & 26,4 & 1,1 & 0,5 & 1,2 & 1,5 & 2 & 2 & 1,3 & 2,4 & 20,3 \\
\hline
\end{tabular}

Fuente: Dirección General de Aguas (DGA). 


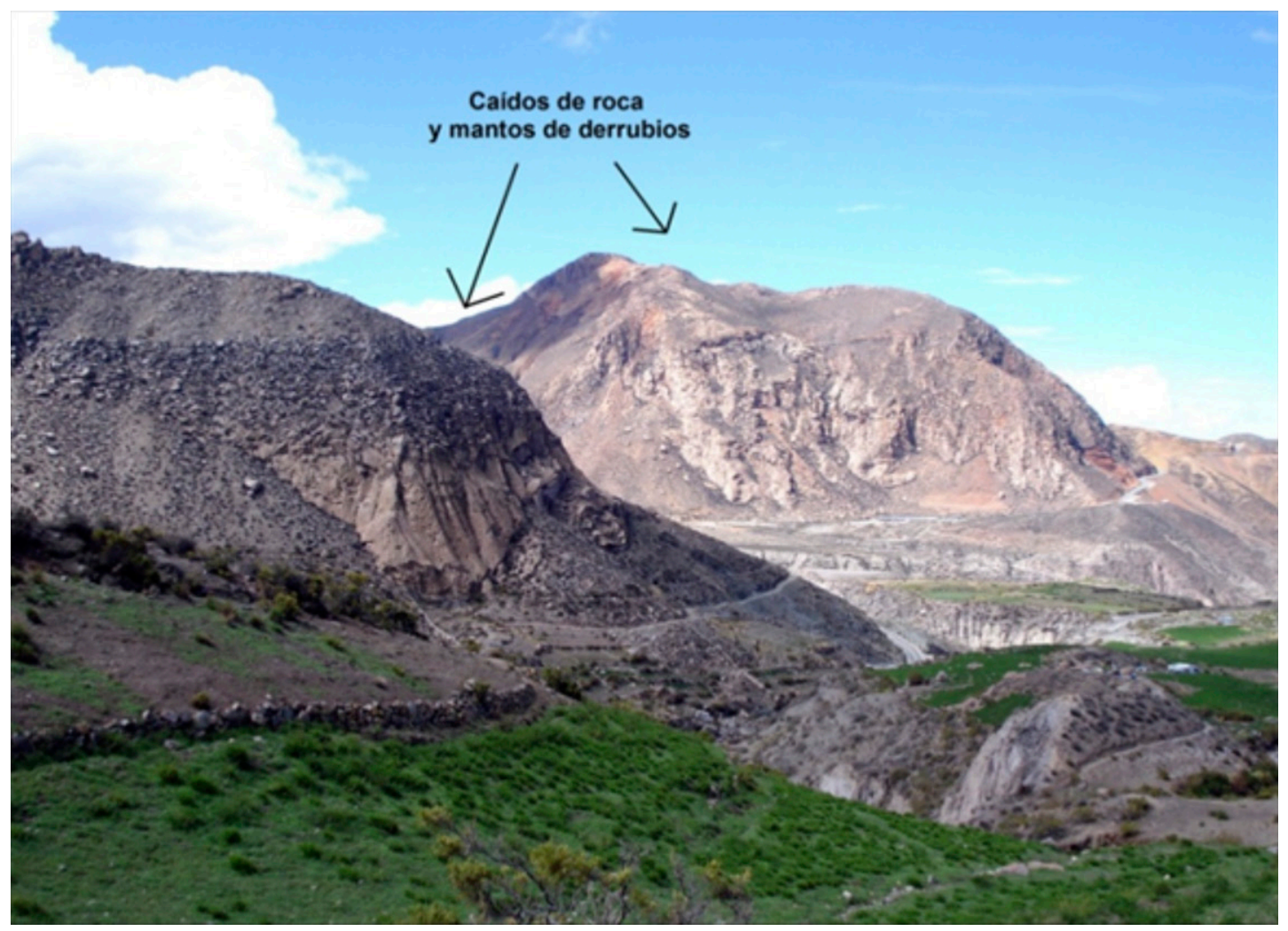

Figura 6. Vista en sentido sureste desde la localidad de Putre. La gran cantidad de material residual que se genera en las laderas es producto de procesos de intemperización, los que aumentan en temporada estival por la infiltración de agua en las diaclasas o juntas. Fuente: archivo de los autores.

El perfil correspondiente al corte A-A' se localiza próximo al CVT, razón por la que la ladera norte presenta una configuración fisonómica muy escarpada y diferencias de altura sobre $500 \mathrm{~m}$; en cambio la ladera sur exhibe una diferencia algo superior a los 200 m y una configuración de pendientes abruptas. El trazo B-B' constituye un corte en la quebrada Taipicagua (río), cuyo perfil está conformado, desde un punto de vista fisiográfico, por laderas de características diferentes, pues la ladera sureste presenta en el sector superior un escarpe que en la sección media se convierte en una ladera ligeramente cóncava, con una diferencia de altura respecto del piso de la quebrada que supera los $250 \mathrm{~m}$; a su vez la ladera noroeste comienza con una escarpadura, para dar paso, posteriormente, a un llano que corresponde a formas de terrazas originadas en los depósitos de las avalanchas volcánicas y que pertenecen a los relieves en los que se localiza el poblado precordillerano de Putre.
El perfil obtenido del corte C-C', localizado al este del área estudiada, presenta formas muy escarpadas y una configuración que comienza a mostrar diferencias desde los $3.600 \mathrm{msnm}$, debido a que la ladera oeste da paso a un relieve más plano, mientras que la vertiente este continúa elevándose sobre los 3.650 msnm Por último, el perfil del corte D-D' representa declives muy pronunciados en la parte terminal de la cuenca, próxima a su confluencia con el río Lluta, en el que se puede observar laderas de pendiente con gran regularidad en el noroeste e irregulares en el sureste. Si se relaciona la forma de la ladera sureste con los procesos geomorfológicos de la Figura 10, se puede entender que esta favorece los procesos gravitacionales que allí se desencadenan, producto de las acentuadas pendientes, surcos de erosión y caídas de roca, lo que estaría coadyuvando por el grado de meteorización de la roca.

Por otra parte, los escurrimientos superficiales episódicos que se circunscriben especialmente a 


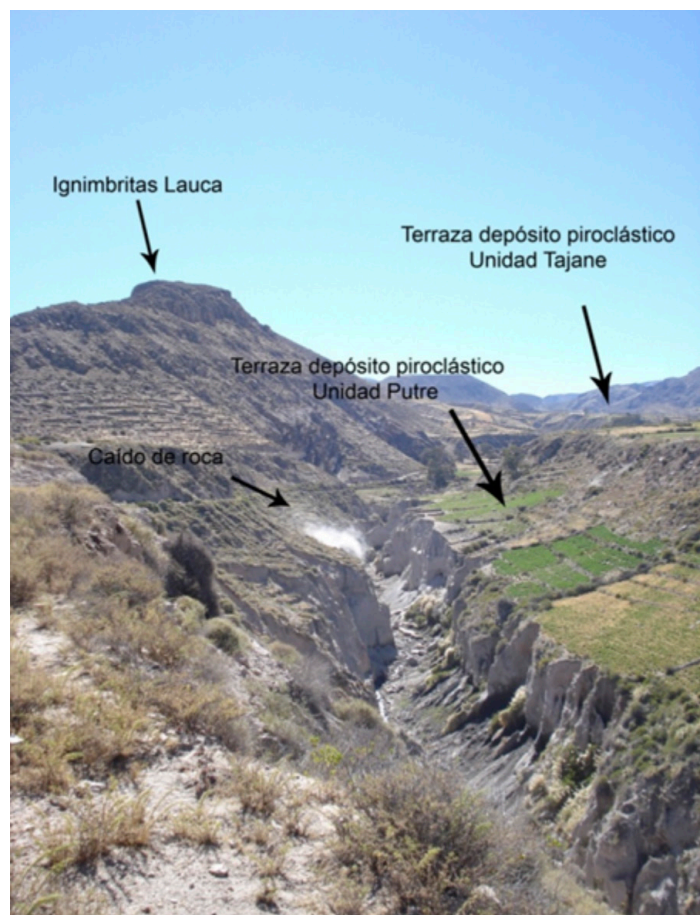

Figura 7. Vista en sentido noreste desde el borde sureste de la Pampa de Lluscuma, se distinguen terrazas de cultivo cercanas a Putre, que se emplazan sobre depósitos piroclásticos de las unidades Tajane y Putre. Las laderas son activas produciéndose constantes caídas de rocas. Fuente: archivo de los autores. las laderas empinadas de la cuenca, corresponden a cursos tributarios de las corrientes permanentes que se activan de dos maneras. Primero, por las lluvias torrenciales en temporada estival, que erosionan y movilizan material mediante sistemas de cárcavas -entendidas también como resultado de la erosión lineal por los cursos de agua episódicos-que culminan generalmente en depósitos de detritos al pie de las laderas, situación que se expresa en el mapa geomorfológico del área. El otro proceso de activación se encuentra asociado al deshielo de los glaciares de montaña situados en las partes altas del CVT y los cerros de Ancoma.

En temporadas estivales, debido al aumento considerable de la pluviosidad, los cursos de agua incrementan su caudal e intensifican la erosión en la base de las vertientes, desestabilizando y provocando movimientos de tierra, lo que los convierte en verdaderos corredores de flujos de barro y escombros (flujos de detritos) alimentados por sedimentos provenientes de las laderas, cuestión que favorece su poder erosivo producto de la mayor carga de material que acarrean en sectores más bajos. Ejemplo de lo señalado se aprecia en la Figura 8, correspondiente a un flujo de detritos de menor magnitud observado en las proximidades a la localidad de Putre.

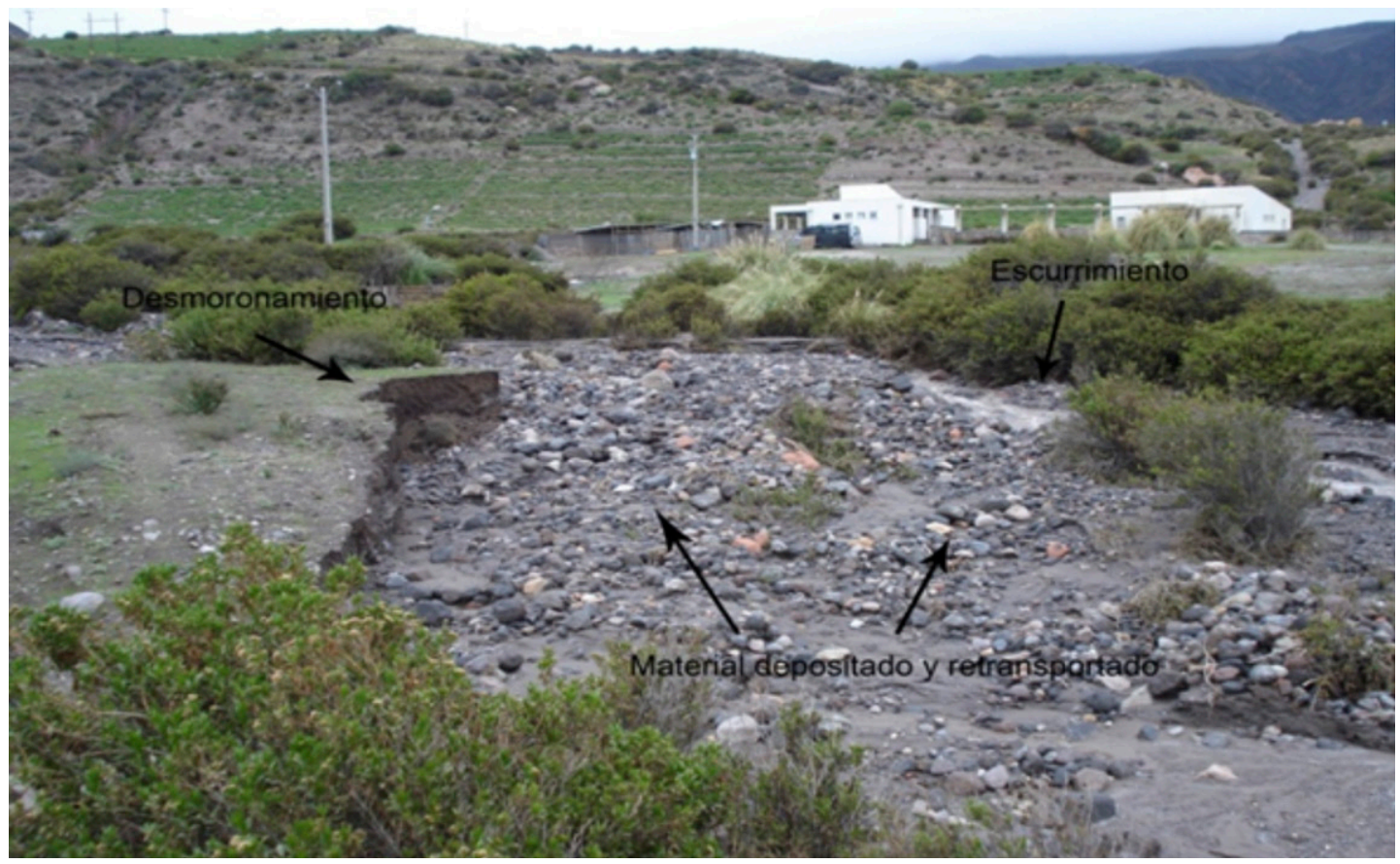

Figura 8. Proximidades de Putre, material residual depositado por escurrimiento superficial. El aumento del flujo de agua acarrea material detrítico que intensifica la erosión de las paredes por zapado mecánico y saturación en las orillas provocando pequeños desmoronamientos. Fuente: archivo de los autores. 

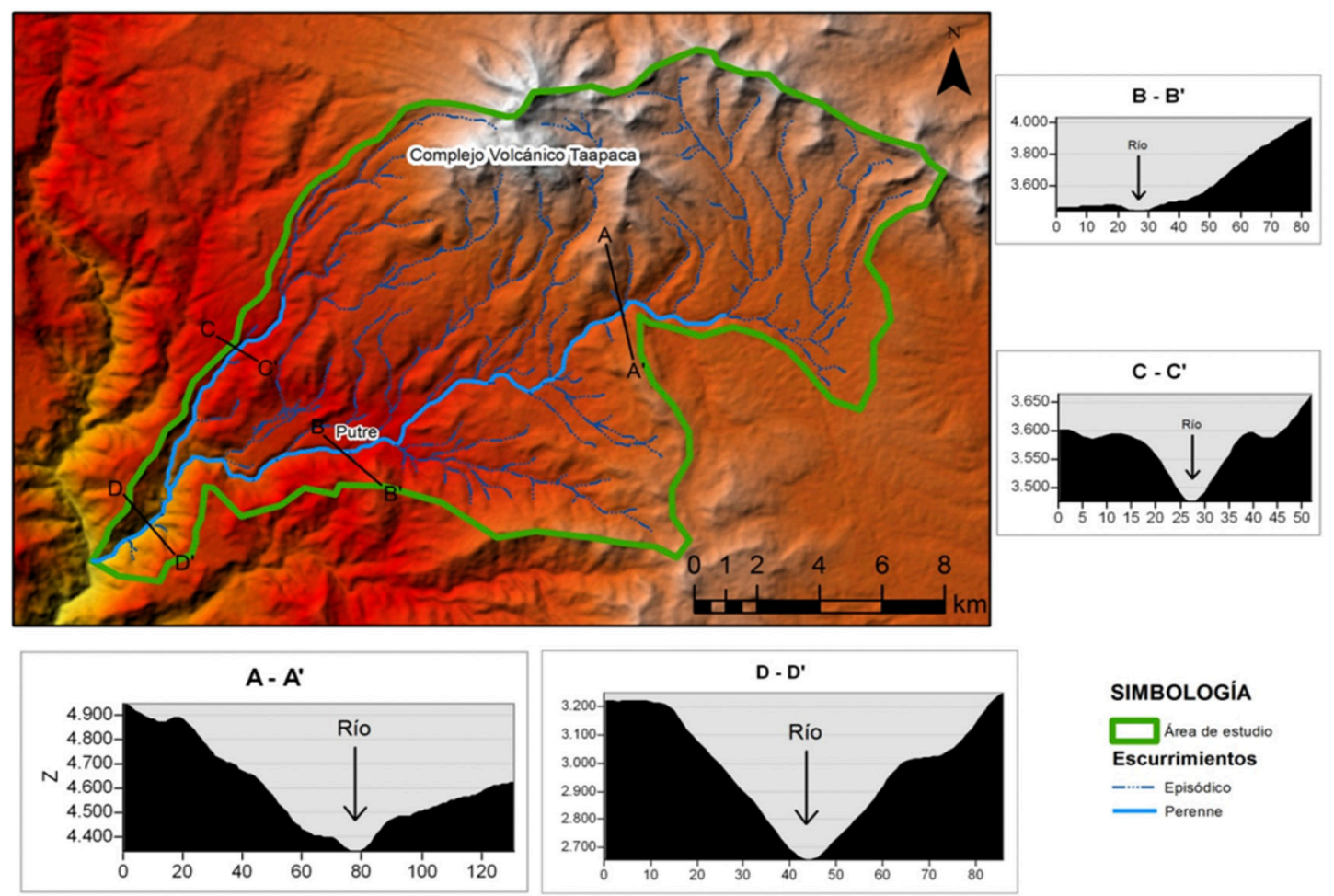

SIMBOLOGÍA

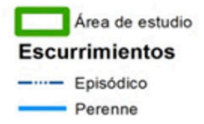

Figura 9. Subcuenca Putre y escurrimientos superficiales. Fuente: elaboración propia.

\section{Geodinámica de las formas}

Los principales factores geomorfológicos que condicionan las formas del terreno de la cuenca son tanto de orden estático como dinámico. Un factor estático lo constituye la litología, que condiciona la efectividad de la fuerza erosiva de los procesos geodinámicos, como sucede por ejemplo en las ignimbritas que componen las laderas de las terrazas volcánicas en que se ubica Putre (Figura 7). Mientras que factores de tipo dinámico se relacionan a la tectónica, el vulcanismo y el clima. La tectónica, asociada a la deformación producida por la subducción entre las placas Nazca y Sudamericana, ha dado paso al cordón volcánico occidental de los Andes, en el que se emplaza el CVT. El vulcanismo, condicionado por la tectónica, ha originado las principales formas de la cuenca, porque las sucesivas erupciones y colapsos del edificio crearon una morfología abrupta alrededor de los puntos emisores. Por su parte, el clima es el factor primordial que desde el inicio del Pleistoceno hasta la actualidad ha provocado cambios en los relieves dentro de la cuenca, donde la naturaleza litológica, y disgregación de los materiales, ha favorecido los diversos procesos de tipo gravitacional y fluvial presentes en el área.

Los principales agentes o medios que favorecen la transferencia de energía en la cuenca son el agua, la gravedad y el magma. El agua modela el terreno por medio de la erosión fluvial, resultado del escurrimiento en los ríos, lo que ha originado profundas quebradas que han erosionado y diseccionado la litología volcánica predominantemente; también lo hace como lluvia, mediante el golpeteo de las gotas de agua en los materiales de las laderas, cuya posterior movilización da paso a erosiones en surco y flujos de detritos, fenómenos influenciados primeramente por la gravedad y después por el agente intermediario (agua) para movilizar material. El magma es un agente endógeno que está presente en la estructura del CVT y las correspondientes formas del relieve, derivadas de los procesos eruptivos y la emisión de lava viscosa, flujos piroclásticos y avalanchas volcánicas (Clavero y Sparks 2005; Clavero et al. 2004a).

Las rocas volcánicas aportadas por violentas erupciones del CVT constituyen un sustrato rocoso 
de lavas viscosas, ignimbritas y brechas volcánicas. Las lavas han configurado un paisaje de domos volcánicos y de flujos que se concentran en las proximidades de los puntos emisores de este material.

Las ignimbritas se extienden sobre el sector sur y suroccidental del CVT, alcanzando lugares apartados al suroeste del poblado de Putre, como la confluencia de la quebrada homónima con el río Lluta. Las ignimbritas de las unidades Tajane, Socapave y Putre se presentan notoriamente erosionadas por la acción de los escurrimientos de agua, que actúan sobre una litología joven, poco consolidada y, por tanto, más proclive a la erosión y a los movimientos de ladera (Figura 7). Las brechas volcánicas son producto de los colapsos volcánicos del CVT, que generaron violentos flujos de escombros que cubrieron los sectores suroccidental y occidental del CVT. Las avalanchas de escombros produjeron morfologías típicas de estas acciones, como anfiteatro del colapso, bloques toreva (grandes bloques de roca deslizados que formaban parte del edificio), hummoky landscapes y terrazas terminales (Clavero y Sparks 2005 y Clavero et al. 2004a). Algunas de estas formas han sido erosionadas y sepultadas tanto por acción de aguaceros estivales como flujos piroclásticos.

Los procesos gravitacionales actuantes sobre las vertientes determinan la ocurrencia de movimientos en masa, entre los que se distinguen principalmente las caídas de roca y los flujos de detritos. Los desplomes de rocas se distribuyen principalmente en aquellos sectores donde existen crestas y cornisas, ya que estas, en general, se componen de salientes rocosas que son meteorizadas, lo que favorece la formación de sistemas de diaclasas que hacen posible el desprendimiento de bloques rocosos (Figura 10).

Sucesivos derrumbes de distintas magnitudes han dado paso a mantos de derrubio y conos de detritos en las laderas. Estos mantos de detritos que se encuentran, por ejemplo, sobre las laderas del CVT generan procesos de reptación gravitacional. Los flujos de detritos -como se ha señalado- se desarrollan en las laderas de alta pendiente y con presencia de material meteorizado inestable proclive a ser transportado y depositado por la acción de las aguas lluvias, y una vez ocurrido el proceso, el material adopta las características formas de conos al acumularse al pie de las laderas (Figura 10).

Los relieves fluviales están conformados por profundas quebradas labradas por los ríos y por los depósitos sedimentarios de los afluentes de los escurrimientos perennes. El transporte y denudación por parte de los ríos ha originado quebradas muy estrechas y con laderas de pronunciadas gradientes, que aportan material residual al transporte de los cursos superficiales. Los afluentes de los cursos principales, que primordialmente se ubican en laderas de grandes pendientes, deben recorrer largos trechos hasta el pie de la ladera, tienden a depositar material detrítico que se extiende por sectores relativamente llanos, lo que se relaciona con procesos dominantes de tipo deposicional (Figuras 10 y 11).

Es así que la geodinámica de la subcuenca hidrográfica de Putre comprende una complejidad morfogenética en la que principalmente han interactuado procesos dominantes como movimientos en masas, fluviales, deposicionales y volcánicos. Indudablemente a los procesos morfoclimáticos se deben agregar los procesos de índole volcánica que han originado el sustrato litológico en el que se han modelado las actuales formas del terreno. De allí que puede sostenerse que la configuración de la cuenca se debe a la acción ejercida por el volcanismo y el clima, factores dinámicos que hasta hoy son responsables del modelado en el área.

Podemos considerar como procesos secundarios, que se articulan con los anteriores para dar la fisiografía actual del área, los de tipo periglaciales y antropogénicos. Los procesos periglaciales se circunscriben primordialmente a los sectores que presentan las mayores elevaciones, donde se producen extensos mantos de material detrítico que son movilizados y transportados por los cursos de agua. En cuanto a los procesos antropogénicos, estos limitan su acción a una superficie muy reducida de la cuenca, que comprende las terrazas terminales de las avalanchas volcánicas, originadas a partir de las erupciones producidas por el CVT. En ellas se encuentran las principales formas antropogénicas que corresponden al poblado de Putre y a los sistemas de andenería de uso agrícola (Figura 1).

\section{Conclusiones}

De acuerdo con los resultados obtenidos, se concluye que el modelado imperante en el piedemonte suroccidental del Complejo Volcánico Taapaca se debe a dos factores dinámicos primordiales: uno volcánico y otro climático. El volcanismo ha condicionado la litología del área estudiada, dando origen, mediante erupciones muy violentas, a una geomorfología estructural donde predominan los domos, flujos de 


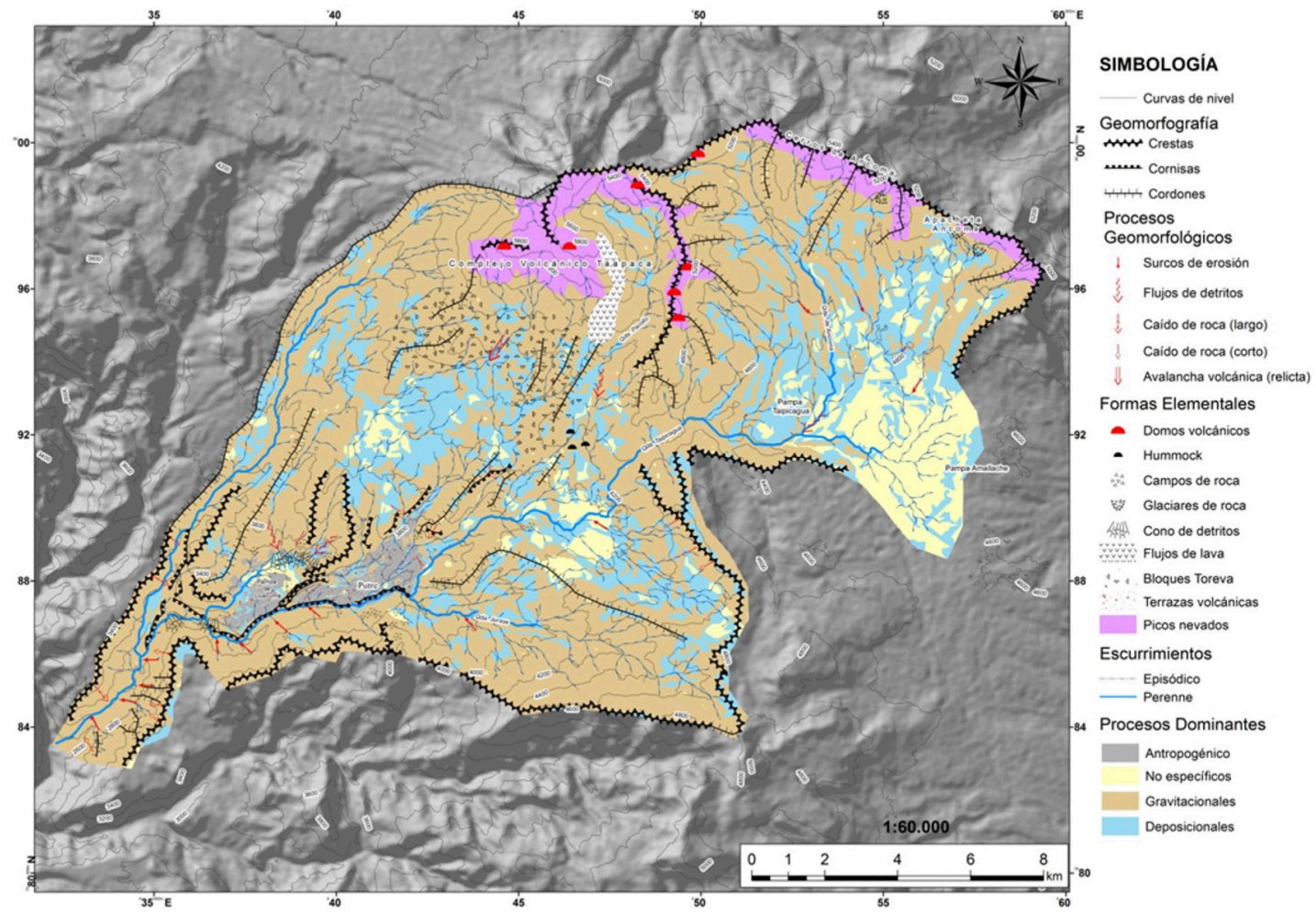

Figura 10. Mapa geomorfológico del área estudiada. Fuente: elaboración propia.

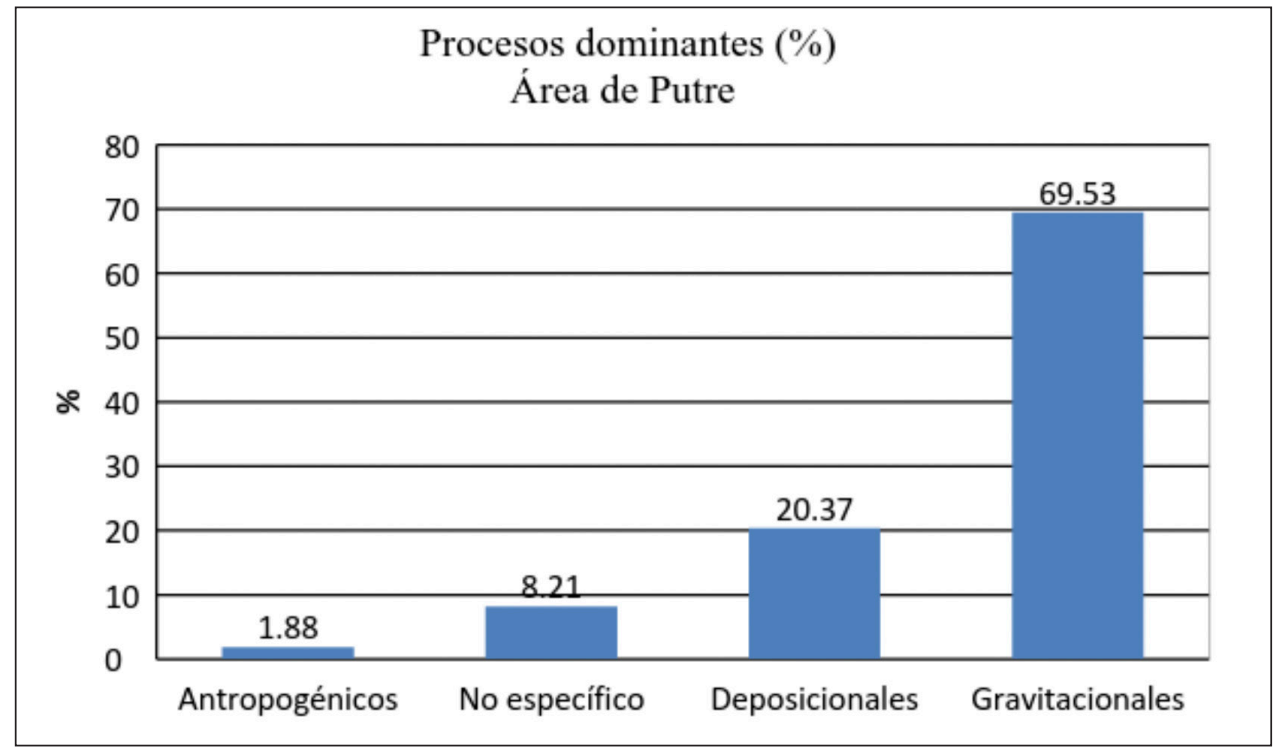

Figura 11. Porcentaje de superficie afectada según el tipo de proceso dominante en el área de Putre. Fuente: Elaboración propia. 
lava, bloques toreva, hummoky landscapes y terrazas. Este conjunto de estructuras se conoce como el Complejo Volcánico Taapaca, cuyos productos ocupan la mayor parte del área investigada.

Por otra parte, el factor climático actuando permanentemente sobre estas morfolitologías constructivas, las meteoriza y erosiona dando como resultado otras formas derivadas que principalmente se relacionan con procesos gravitacionales, fluviales y periglaciales. Entre este conjunto de procesos morfogenéticos interrelacionados destacan los fenómenos de movimiento en masa, que cubren el 69\% del área estudiada, y entre los que se reconocen flujos de detritos, derrumbes y surcos de erosión, procesos a los que los derrubios en las laderas han contribuido.

Estos mecanismos y formas resultantes se relacionan con las grandes oscilaciones de temperatura que se presentan a lo largo del año, las que posibilitan las acciones de desagregación y fragmentación.
En suma, los procesos geomorfológicos y el continuo modelado del relieve tienen en el factor climático el principal agente que configura la fisiografía actual de la subcuenca Putre, sin embargo una posible reactivación del Complejo Volcánico Taapaca podría volver a condicionar la acción erosiva de los componentes del clima.

\section{Agradecimientos}

Los autores agradecen los comentarios y correcciones de los catedráticos Dr. Juan José Sanz Donaire y Dr. Javier de Pedraza Gilsanz de la Universidad Complutense de Madrid; las críticas y aportes de referencias bibliográficas de los geólogos Miguel Cáceres Munizaga y Benigno Godoy Neira; y los consejos para la confección del mapa geomorfológico ofrecidos por el Dr. Jan-Christoph Otto de la Universität Salzburg.

\section{Referencias Citadas}

Aceituno P.

1993. Aspectos generales del clima en el altiplano sudamericano. Actas del II Simposio Internacional de Estudios Altiplánicos, Arica-Chile. pp. 63-69.

Bennett, M.; New, M.; Marino, J. \& Sillero-Zubiri C.

2016. Climate complexity in the Central Andes: A study case on empirically-based local variations in the dry Puna. Journal of Arid Environments 128:40-49.

Börgel, R.

1983. Geomorfología. Geografía de Chile. Tomo II. Instituto Geográfico Militar, Chile.

Clavero, J.

2007. Peligros del Complejo Volcánico Taapaca, Región de Arica y Parinacota. Servicio Nacional de Geología y Minería, Carta Geológica de Chile, Serie Geología Ambiental 10, 1 mapa escala 1:50.000.

Clavero, J.; Sparks, R.S.J.; Huppert, H.E. y Dade, W.B.

2002. Geological constraints on the emplacement mechanism of the Parinacota debris avalanche, northern Chile. Bull Volcanol 64:40-54.

Clavero, J.; Sparks, R.S.J.; Pringle, M.S.; Polanco, E. y Gardeweg, M.C.

2004a. Evolution and volcanic hazards of Taapaca Volcanic Complex, Central Andes of Northern Chile. Journal of the Geological Society 161: 603-618.

Clavero, J.; Sparks, R.S.J.; Pringle, M.S. y Polanco, E. 2004b. Evolution of Parinacota volcano, Central Andes, Northern Chile. Andean Geology 31(2):317-347.

Clavero, J. y Sparks, R.S.J.

2005. Geología del Complejo Volcánico Taapaca, Región de Tarapacá. Servicio Nacional de Geología y Minería, Carta Geológica de Chile, Serie Geología Básica, No 93, 23 p., 1 mapa escala 1:50.000.
Fuenzalida, $\mathrm{H}$

1965. Clima. En Geografía Económica de Chile. Texto refundido. pp. 99-152. Corporación de Fomento de la Producción, Chile.

García, M.; Gardeweg, M.; Clavero, J. y Hérail, G.

2004. Hoja Arica, Región de Tarapacá. Servicio Nacional de Geología y Minería, Carta Geológica de Chile, Serie Geología Básica, 1 mapa escala 1:250.000.

Godoy B.; Clavero, J.; Rojas, C. y Godoy, E.

2012. Facies volcánicas del depósito de avalancha de detritos del volcán Tata Sabaya, Andes Centrales. Andean Geology 39(3):394-406.

Godoy, B.

2008. Análisis estructural y de facies del depósito de avalancha de detritos del volcán Tata Sabaya, Andes Centrales, Bolivia. Memoria para optar al título de Geólogo (Inédita), Universidad Católica del Norte, Antofagasta, Chile.

Golubev, G.

1969. Avalanchas y corrientes de barro en Chile. Revista Informaciones Geográficas 17:31-74.

Hauser, A.

1993. Remociones en Masa en Chile. Servicio Nacional de Geología y Minería, Boletín 45, Santiago, Chile. JICA

1995. The Study on the Development of Water Resources in Northern Chile. Main Report, Supporting Report A: Surface Water. Pacific Consultants International, Japan International Cooperation Agency, Japón.

Mendonça, $\mathrm{M}$.

2013. Monzón sudamericano: La integración de la circulación amazónica y altiplánica y las variabilidades climáticas del altiplano andino chileno. En: XIV Encuentro de Geógrafos de Latinoamérica (Lima, 8-12 de abril de 2013): Reencuentro de Saberes Latinoamericanos. Lima. 
Meseguer-Ruiz, O.; Corvacho, O.; Tapia Tosetti, A.; LópezCepeda, J.F. y Sarricolea, P.

2016. Tendencias de la temperatura mensual y de los extremos diarios durante el período 1966-2015 en el norte grande chileno. En: Olcina Cantos, Jorge; Rico Amorós, Antonio M.; Moltó Mantero, Enrique (eds.). Clima, sociedad, riesgos y ordenación del territorio. Alicante: Instituto Interuniversitario de Geografía, Universidad de Alicante, Asociación Española de Climatología, pp. 257-266.

Montecinos, F.

1962. Grietas y deslizamientos de tierra en la región de Socoroma departamento de Arica. Instituto Investigaciones Geológicas, Santiago, Chile.

Niemeyer, H. y Cereceda, P.

1983. Hidrografía. Geografía de Chile. Tomo VIII. Instituto Geográfico Militar, Chile.

Otto, J. y Dikau, R.

2004. Geomorphologic system analysis of a high mountain valley in the Swiss Alps. Zeitschrift für Geomorphologie 48:323-341.

Otto, J.; Gustavsson, M. y Geilhausen, M.

2011. Symbolisation and Visualisation of Geomorphological Maps. Chap. 9; en: Smith, M., Paron, P. y Griffiths, J. Geomorphological Mapping. Methods and Applications, Elsevier, p. 253-295.

Otto, J. y Smith, M.

2013. Geomorphological mapping. British Society for Geomorphology, Geomorphological Techniques, Chap. 2, Sec. 6 .

Rodríguez, A.; Tapia, A. y Albornoz, C.

2014. Susceptibilidad de Movimientos en Masa en el Valle de Socoroma, Precordillera Andina de Arica y Parinacota. Diálogo Andino 44:25-39.

Rodríguez, I.

2010. Estudio de facies y análisis de parámetros físicos del depósito de avalancha de detritos del volcán Llullaillaco,
Andes Centrales. Memoria para optar al título de Geólogo (Inédita), Universidad Católica del Norte, Antofagasta, Chile.

Sarricolea, P. y Romero H.

2015. Variabilidad y cambios climáticos observados y esperados en el Altiplano del norte de Chile. Revista de Geografía Norte Grande, 62:169-183.

Seijmonsberger A. y Graaff W.

2006. Geomorphological mapping and geophysical profiling for the evaluation of natural hazards in an alpine catchment. Natural Hazard and Earth System Sciences 6:185-193.

Seydried, E.; Wörner, G.; Uhlig, D.; Kholer I. y Calvo C.

1998. Introducción a la geología y geomorfología de los Andes en el norte de Chile. Chungara 30 (1):7-39.

Siebert, L.

1984. Large volcanic debris avalanches: characteristics of source areas, deposits, and associated eruptions. Journal of Volcanology and Geothermal Research 22:163-197.

Stern, C.

2004. Active Andean Volcanism: its geologic and tectonic setting. Andean Geology 31 (2):161-206.

Suárez, J.

2010. Deslizamientos: Análisis geotécnico. Volumen 1. Universidad de Santander, Colombia.

Tilling, L.

2009. Volcanism and associated hazard: the Andean Perspective. Advances in Geosciences 22:125-137.

Watts, R.; Clavero, J. y Sparks, R.S.J.

2014. The origin and emplacement of Domo Tinto, Guallatiri volcano, Northern Chile. Andean geology, 41(3): 558-588.

Wörner, G.; Harmon, R.S.; Davidson, J.; Moorbath, S.; Turner,

D.L.; McMillan, N.; Nye, C.; López-Escobar, L. y Moreno, H. 1988. The Nevados de Pachayata volcanic region $\left(18^{\circ} \mathrm{S} / 69^{\circ} \mathrm{W}\right.$, N. Chile). I Geological, geochemical and isotopical observations. Bulletin of Volcanology, 50: 287-303. 